spirit of international good-fellowship and understanding prevailed throughout the meeting.

Sixteen well-attended dinners were held during the meeting by the various groups of scientific workers. The programmes of the sections and of the societies associated with them were generally extensive, and all were interesting and important. Many vice-presidential and presidential addresses were given and many symposia held. Special mention should be made here of the fine programme of Section M (Engineering) and of the symposium on an international auxiliary language, which was arranged for Toronto under the auspices of Section K (Social and Economic Sciences). The engineering programme was unusually excellent in many ways. Arrangements for this were due to the very efficient work of Mr. J. B. Tyrrell, of Toronto, vice-president of Section M. The Society for the Promotion of Engineering Education met with Section M.

The social and economic sciences (Section $\mathrm{K}$ ) had no separate programme, but through the enthusiastic and efficient work of Dr. F. G. Cottrell, of the U.S. National Research Council, a symposium on an international auxiliary language was arranged. This was held at a joint session on Friday afternoon of Sections $K$ and $Q$ (Education). The symposium was preceded by the address of the retiring vice-president of Section K, Dr. F. L. Hoffman, of the Prudential Life Insurance Co. of America, on "The Organisation of Knowledge."

A programme of great general and cultural interest was presented by the Committee on the History of Science in a session held on Thursday morning. Among others, Dr. J. P. McMurrich-afterwards elected president of the association for $1922-$ gave a paper on the artistic anatomical work of Leonardo da Vinci.

The extraordinary success of the meeting was due mainly to the tireless and varied activities of the members of the local committee under the chairmanship of Prof. J. C. Fields, who foresaw all needed arrangements and added many pleasant and convenient details. Especially was praise given to the very artistic official badge, which will serve as a worthy commemoration of one of the most satisfactory meetings of the association. The very onerous and pressing work of caring for the publication of the general programme was undertaken by Dr. J. P. McMurrich, who handled this very difficult and confusing complex of details with very great skill. The University of Toronto Press gave very efficient service in this connection.

Publicity was unusually well handled. The recently organised Science Service co-operated with the association in arousing public interest in the meeting through the daily press. Dr. E. E. Slosson, editor of Science Service, and Mr. Watson Davis were present throughout the meeting on behalf of Science Service. Besides the valuable publicity work of Science Service, which is under the control of the American Association, the U.S. National Academy, and the U.S. National Research Council, and which operates for the sole purpose of disseminating scientific knowledge through the newspapers, just as valuable and efficient publicity work was accomplished by the local SubCommittee on Publicity, of which Prof. A. G. Huntsman was chairman.

At the council meeting of the association the sum of 4000 dollars was allocated in grants for research, according to the recommendations of the committee on grants. Prof. B. K. Emerson, of Amherst, Mass., and Prof. E. A. Smith, of the University of Alabama, were elected to emeritus life-membership on account of the Jane M. Smith Endowment Fund. On a vote by the council the president appointed the following committee to consider the subject of reciprocity between the United States and Canada so far as this concerns scientific work :-E. L. Nichols (chairman), F. D. Adams, T. C. Chamberlin, J. C. Fields, and J. C. Merriam. It was decided that the next annual meeting of the association should be held at Boston, Mass., on December 26-30, I922, and the I923-24 meeting at Cincinnati, Ohio, in December 1923.

Dr. J. P. McMurrich, professor of anatomy in the University of Toronto, was elected president of the association. The following vice-presidents of the several sections were elected :-A (Mathematics), G. A Miller, University of Illinois; B (Physics), Frederick A. Saunders, Harvard University; C (Chemistry), W. Lash Miller, University of Toronto; D (Astronomy), Otto Klotz, Dominion Observatory, Ottawa, Ontario; E (Geology and Geography), Charles P. Berkey, Columbia University ; F (Zoological Sciences), Maynard M. Metcalf, Oberlin College; G (Botany), Francis E. Lloyd, McGill University ; I (Psychology) Raymond Dodge, Wesleyan University; $\mathrm{K}$ (Social and Economic Sciences), Henry S. Graves, Washington, D.C. ; L (Historical and Philological Sciences), William A. Locy, Northwestern University ; M (Engineering), George F. Swain, Harvard University; N (Medical Sciences), Francis W. Peabody, Harvard Medical School ; and O (Agriculture), R. W. Thatcher, University of Minnesota.

Burton E. Livingston.

\title{
The Use of Light as an Aid to Aerial Navigation.
}

$A^{T}$ the meeting of the Illuminating Engineering Society on January 3r, Lt.-Col. L. F. Blandy, who is associated with the Air Ministry, delivered a paper on "The Use of Light as an Aid to Aerial Navigation." Gen. Sir Frederick Sykes, ControllerGeneral of Civil Aviation, presided. In the introductory portion of the paper the author described the lighting of the passengers' accommodation and crew's quarters, etc., on a modern airship, the light being derived from electric lamps fed from a generator driven by the engine. Small candle-power lamps are used for illuminating the dials of instruments, etc., on some machines. The external lighting of aircraft has been closely studied by the International Air Convention, which has defined precisely the equipment of a forward white light of $8-\mathrm{km}$. range, a red light of at least $5-\mathrm{km}$. range on the left hand, and a green light of similar range on the right. Special arrangements must be made to prevent the green light being seen from the left side or the red light from the right. A white rear light is also provided.

In navigating the air, principles similar to those in use at sea are thus being adopted for external lights, but owing to the motions of aircraft and their high speed the arrangement of navigation lamps demands special care. The relative speed of approaching machines may attain 200 m.p.h., i.e. 3.3 miles per minute. From the time of sighting headlights to the moment of collision the time available may be only 90 seconds, and it looks as though the range of navigation lights may have to be increased. Lights used by aircraft to facilitate landing may be either chemical or electric. Gas-filled electric lamps of Iooo-2000 c.p. have been developed for this purpose, and appear to have some advantages over flares, notably as regards ease of control and extinction at will. Aerodrome lighting includes lights used to define the positions of buildings and other obstruc- 
tions, illumination of the actual ground, and fixed illuminated signs to show the position of wind, etc. At Croydon the lighting of high wireless masts, which form dangerous obstructions, has been effected by placing Iooo-c.p. gas-filled lamps, screened red, on the top of the masts. These form a good recognition mark.

Ground illumination requires special care to avoid dazzling the eyes of pilots at some angles. A special arrangement recommended at the International Air Convention is the use of lights arranged in the form of two "L's" to indicate positions for "taking off" and landing. Such lights were originally mounted in reflectors covered by flat glass discs in such a way that they were readily visible from above, but invisible at close range. Better methods of diffusion, enabling lights to be seen at all angles, have since been devised. Searchlights appear helpful, but have to be used with care to avoid confusing shadows when the machine is near the ground. An appendix to the paper contains particulars of the recommendations of the International Air Convention in regard to signals of distress, etc. Much has yet to be done in this new field, but the paper affords a useful review of existing procedure.

\section{The Preservation of Stone.}

AECTURE to the Royal Society of Arts on the
above subject by Mr. Noel Heaton is published in the Journal of the society for December 30 last. The lecturer gave an account of the various attempts which have been made to solve the important problem of preventing the decay and disintegration of stonework in buildings. The great majority of modern stone buildings, and a still greater proportion of medieval buildings, are constructed of limestone or sandstone, and the problem centres around these varieties rather than about the more resistant granite, used only to a limited degree. The causes of disintegration may be natural, depending on fluctuations of temperature, on rain, on erosion by wind, and, in ferruginous sandstones, on oxidation. Minute differences in structure often cause great differences in durability. The growth of vegetation on stone usually hastens decay. The most potent cause of decay is, however, the " unnatural " action of sulphuric acid, derived from coal-smoke, coupled with the accumulation of soot and grime. Sir Frank Baines, who introduced the lecturer, stated that, roughly, 80 ,ooo tons of sulphuric acid are thrown annually into the London atmosphere. Strain set up by the rusting of iron is also a contributory cause of decay. The lecturer then turned to the means of preventing decay.

An indirect method of preventing decay is to further, by every possible means, the campaign against atmospheric pollution. The stone may be treated with preservatives, which were divided into three groups: (a) those acting merely as surface coatings; (b) those impregnating the stone without chemical action; and $(c)$ those operating by chemical reaction with the stone. In the first class are paint and limewash, the latter being useful where the stone is subjected to a moist atmosphere, but protected from rain. In the second class are mineral wax applied by heat or in solution in benzene, drying oils, creosote, or gelatinous precipitates formed on the stone. The first process is very old, and is effective for certain purposes. Treatment with alum solution, followed by soft soap, which results in the precipitation of an aluminium salt of the fatty acids, is recommended.

In the third class treatment with baryta is effective in repairing a stone disintegrated by sulphuric acid. A common method is the deposition of silica or silicates. Treatment with waterglass leads to unsightly efflorescence. This may be reduced by treating with a solution of arsenic acid after the waterglass, but the most satisfactory results are obtained with silicofluorides, introduced in France by Kessler in 1883 . A solution of magnesium silicofluoride reacts with limestone :

$$
\mathrm{MgSiF}_{6}+2 \mathrm{CaCO}_{3}=\mathrm{SiO}_{2}+\mathrm{MgF}_{2}+2 \mathrm{CaF}_{2}+2 \mathrm{CO}_{2} .
$$

The solution, known as "Fluate," is manufactured in France, and the lecturer stated that, although the results were conflicting, it appeared to be beneficial. In America the double salts of magnesium and zinc were preferred. The use of the solution has recently been investigated by Prof. Desch, in conjunction with the Department of Scientific and Industrial Research, and, although the detailed results have not yet been published, the conclusions appear to be that too strong a solution should not be used (not stronger than Io per cent.), and that the mode of application should be adjusted to particular conditions. The method is most useful on new work. The use of nostrums of unknown composition is strongly condemned, as they may cause great injury. Sir Frank Baines also contributed some valuable information in the discussion on the lecture.

\section{Mathematics in Japan.}

A GOOD many years ago there was an exhibition at Earl's Court in which the Japanese Government and nation took a conspicuous part. For several reasons the Japanese art section was particularly interesting. It contained priceless and authentic specimens of their national painting and handicraft before they were influenced by foreign methods and ideals. Besides this, there were paintings by some of their modern artists who adopted Western methods and conventions. The contrast was very striking, and in some respects not very satisfactory.

Similar reflections are suggested by the present state of Japanese mathematics, as shown, for example, in various mathematical papers recently received from the University of Tokyo. Circumstances are different because mathematical science is now cosmopolitan, and no single nation can afford to neglect its various developments. At the same time, like nationality in drinks, there is a kind of nationality in science, art, or any other human activity, which is justifiable, and even instructive, if it is not carried to excess. We may notice it, for example, in the papers and treatises of the leading mathematicians, such as Klein and Dedekind on one hand and Poincaré, Hermite, and Darboux on the other. The elegance of the best French text-books is scarcely equalled, if at all, by those of any other nation; at the same time, the corresponding German works are distinguished by thoroughness, method, and fulness of references. The treatise on elliptic modular functions by Klein and Fricke and Poincaré's memoirs on Fuchsian functions illustrate the point.

It is difficult to be sure how far Japanese mathematics is entirely original. They had various approximations to $\pi$, some of which, at any rate, seem to have been of their own invention. They had an extraordinary gift for solving numerical equations of high degrees by approximation, and one Japanese writer appears to have anticipated many of Steiner's 